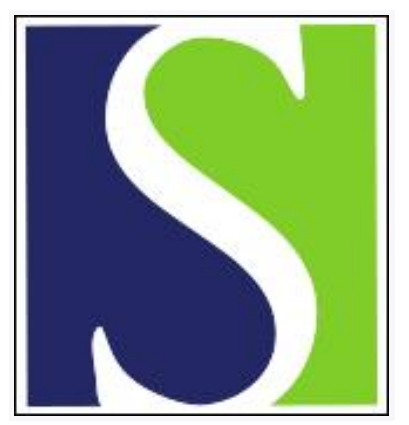

Scand J Work Environ Health 2008;34(6):420-429

https://doi.org/10.5271/sjweh.1298

Issue date: 00 Dec 2008

Predictors of sick leave and reduced productivity at work among persons with early inflammatory joint conditions

by Geuskens GA, Hazes JMW, Barendregt PJ, Burdorf A

Affiliation: Department of Public Health, Erasmus MC University Medical Center Rotterdam, PO Box 2040, NL-3000 CA Rotterdam, Netherlands. [E-mail: g.geuskens@erasmusmc.nl

The following articles refer to this text: 2009;35(4):301-308;

2010;36(1):1-2; 2015;41(1):102-104; 2018;44(5):521-529

Key terms: arthritis; inflammatory joint condition; joint condition; pain; performance at work; physical functioning; physical workload; predictor; productivity; prospective cohort study; reduced productivity; sick leave; supervisor; support; work

This article in PubMed: www.ncbi.nlm.nih.gov/pubmed/19137203 


\title{
Predictors of sick leave and reduced productivity at work among persons with early inflammatory joint conditions
}

\author{
by Goedele A Geuskens, MSc, ${ }^{1,2}$ Johanna MW Hazes, MD, ${ }^{1}$ Pieternella J Barendregt, MD, ${ }^{1}$ Alex Burdorf, \\ $P h D^{2}$
}

Geuskens GA, Hazes JMW, Barendregt PJ, Burdorf A. Predictors of sick leave and reduced productivity at work among persons with early inflammatory joint conditions. Scand J Work Environ Health 2008;34(6):420-429.

\begin{abstract}
Objectives This study attempted to identify predictors of sick leave and reduced productivity at work among persons with early inflammatory joint conditions.

Methods In a prospective cohort study of 210 workers with inflammatory joint conditions present for less than 12 months, data were collected by a medical examination and questionnaires at baseline and after 6 and 12 months. The outcomes were sick leave and reduced productivity at work. Generalized estimation equations (6-month time-lag model) were used to study predictors.

Results Sick leave was predicted by high levels of pain [odds ratio (OR) 3.2], poor physical functioning (OR 4.4), and frequent manual materials handling (OR 2.0), whereas supervisors had a lower likelihood of sick leave (OR 0.2). The predictors of reduced productivity at work were intermediate levels of pain (OR 3.1), poor physical functioning (OR 2.8), poor mental health (OR 2.1), and low support from colleagues (OR 2.2), whereas the workers classified as having nonrheumatoid arthritis were less likely to report reduced productivity than those with inflammatory joint complaints without clinical synovitis (OR 0.4).

Conclusions Among the workers with early inflammatory joint conditions, self-reported pain and physical functioning affected performance at work, together with manual materials handling and lack of support from colleagues. Early treatment should target pain and physical functioning, and job interventions should aim at reducing physical workload and increasing coworker support.
\end{abstract}

Key terms arthritis; pain; performance at work; physical functioning; physical workload; prospective cohort study; supervisor; support.

Worklife expectancy among persons with arthritis or rheumatism is about 4.2 years lower for men and 3.1 years lower for women (1). For rheumatoid arthritis, ankylosing spondylitis, and psoriatic arthritis, employment ratios range from 0.78 to 0.94 when compared with the employment ratio of the general population (2). Among persons with longstanding rheumatoid arthritis, the prevalence of (partial) work disability pensions is $11 \%$ to $52 \%$ higher than in the general working population (3). The long-term effects of clinical characteristics, physical function, and physically demanding work on work disability have been well documented, especially for rheumatoid arthritis patients $(4,5)$. However, the performance at work (ie, sick leave and productivity at work) among employees with rheumatic diseases is increasingly gaining attention (6-8).
Sick leave and reduced productivity at work reflect a reduced capacity to meet the demands of the job. Sick leave is more frequently observed among workers with chronic arthritis or related joint disorders (9-12). Among employees with musculoskeletal conditions, risk factors for sick leave include pain intensity, reduced function, demographic factors, high physically demanding work, high job strain, and low support at work (13-18). In addition to sick leave, $\mathrm{Li}$ et al (19) found that $49 \%$ of workers with longstanding arthritis reported reduced productivity at work. In accordance, Burton et al (20) reported that workers with chronic arthritis who received treatment had a $2.5 \%$ reduction in productivity at work due to arthritis. They were 1.5 times more likely to report reduced productivity in physical activities than workers without arthritis (20).

1 Department of Rheumatology, Erasmus MC, University Medical Center Rotterdam, Rotterdam, Netherlands.

2 Department of Public Health, Erasmus MC, University Medical Center Rotterdam, Rotterdam, Netherlands.

Correspondence to: Dr A Burdorf, Department of Public Health, Erasmus MC University Medical Center Rotterdam, PO Box 2040, NL-3000 CA Rotterdam, Netherlands. [E-mail: a.burdorf@erasmusmc.nl] 
Sick leave may precede work-relevant disability among people with rheumatic diseases $(21,22)$. Besides, reduced performance at work importantly contributes to indirect costs $(6,19)$. However, thus far, no prospective study has addressed the relative contribution of clinical, individual, and work characteristics to sick leave and reduced productivity at work among persons with recent inflammatory joint conditions. Especially concerning an early phase of inflammatory joint conditions, knowledge of these predictors is of interest, since work and disease characteristics may be amendable to change as a part of early tertiary intervention. Hence the aim of this study was to identify predictors of sick leave and reduced productivity at work among workers with early inflammatory joint conditions.

\section{Study population and methods}

\section{Study population}

The current study presents the 1-year follow-up data of the Rotterdam early arthritis cohort (REACH). REACH is an ongoing inception cohort study with 4 years of follow-up. Its objective is to study the ethiopathogenesis, diagnostic strategies, and outcome of patients with inflammatory joint conditions for less than 12 months. Altogether 82 general practitioners, 12 rheumatologists, and 4 rheumatologist trainees (1 university hospital, 2 general hospitals) in the greater area of Rotterdam have invited patients to participate in REACH from July 2004 on. The data collection included a large array of detailed medical examinations and questionnaires. When patients enter the study, they can choose to provide only limited medical data or self-reported questionnaires or both. For the current study, the patients who were sent by general practitioners or rheumatologists for inclusion in the study up to July 2006 were studied. This date was chosen to ensure that 1-year follow-up data on these patients were available for analysis.

General practitioners selected patients with clinical synovitis in at least one joint or patients experiencing complaints in at least two joints without synovitis. The general practitioners ascertained that the complaints had existed for less than 12 months and were not due to trauma or mechanical problems. During a telephone interview and a subsequent medical examination by a rheumatologist, the inclusion criteria were verified. Patients were included if (i) joint complaints existed for less than 12 months with no requirement of a minimum duration and (ii) clinical synovitis in at least one joint or complaints in at least two joints in combination with at least two of the following criteria ascertained during a medical examination by a rheumatologist: morning stiff- ness longer than 1 hour, bilateral compression pain in the metacarpophalangeal joints or metatarsophalangeal joints, symmetrical presentation, positive family history, no longer fitting own shoes, no longer fitting own rings, pins and needles in fingers, or unexplained fatigue for less than 1 year, and (iii) complaints were predominantly present in the morning and at night, and improved with movement. Patients were excluded if (i) complaints were due to trauma or mechanical problems, (ii) age was under 16 years, (iii) no written communication was possible in Dutch, or (iv) a prior diagnosis of rheumatoid arthritis, ankylosing spondylitis, Sjögren's syndrome, systemic lupus erythematosus, or juvenile arthritis had been made by a rheumatologist before inclusion in the study. For patients directly visiting rheumatologists, a similar verification procedure was applied. For all of the patients, enrolled through general practitioners or rheumatologists, a rheumatologist set the diagnosis.

Altogether 586 patients had been notified by the end of July 2006 (figure 1). A total of 122 patients did not fulfill the inclusion criteria. Before actual inclusion, 44 patients were lost. These patients were significantly more often male than the participants (39\% versus $27 \%$ male), but no differences in age existed. After inclusion, 61 of the 420 patients (15\%) were excluded from the current study due to incomplete data collection (5\%) or the patient's choice at his or her entrance into the study to provide only limited medical data or self-reported questionnaires $(10 \%)$. The age and gender of these patients did not differ significantly. Since only patients aged 18 to 65 years in paid employment were selected for the current study, 210 patients were included. This study was approved by the ethics committees of the three participating hospitals. All of the patients gave their written informed consent.

\section{Measurements}

At the baseline and after 6 and 12 months of follow-up, the patients completed self-administered questionnaires, and clinical characteristics were obtained in a medical examination.

\section{Demographic and work characteristics}

Age, gender, and ethnicity were asked about. Ethnicity was categorized into Dutch origin (no parent born abroad) or non-Dutch origin (at least one parent born abroad) (23). Education was categorized according to the highest level attained into low ( $\leq 9$ years: primary school, lower and intermediate secondary schooling or lower vocational training), intermediate (10-14 years: higher secondary schooling or intermediate vocational training), and high ( $\geq 15$ years: higher vocational training or university). 
Work characteristics were assessed at baseline and if patients changed jobs during the follow-up period. Full-time employment was defined as working at least 36 hours per week. The patients were asked whether they were a supervisor or self-employed and whether they worked in shifts. The duration of employment for the same employer was dichotomized on the basis of the median number of years (24). Physical load was assessed by questions derived from the Dutch Musculoskeletal Questionnaire on manual materials handling (lifting $5 \mathrm{~kg}$ or lifting $25 \mathrm{~kg}$ or both), strenuous arm positions (working with hands above shoulder level or repetitive arm movements), and clerical work (prolonged sedentary work and computer work) $(24,25)$. Answers were recorded on a 4-point scale with ratings "seldom or never", "now and then", "often", and "always". The answers "often" and "always" were classified as high exposure (25). Physical exertion was rated at each measurement on a numerical rating scale from 0 ("no effort at all") to 10 ("very high effort"). A score of $\geq 6$ was classified as high physical exertion (26).

Questions on the psychosocial load of the job were derived from the Karasek model (27). In this model, people are supposedly at risk for psychological strain when experiencing high job demands and low job control. Job demands were measured by 11 items (eg, working fast, excessive work). Job control was measured by 6 items on skill discretion (eg, task variety, learning new things), and by 11 items on the authority to make decisions (eg, autonomy in executing tasks and solving problems, influence on planning). For both dimensions, the sum score was dichotomized according to the median score.

Support from colleagues was measured by a numerical rating scale ranging from 0 (no support) to 10 (high support). Support from the supervisor was similarly ascertained (28). On the basis of the median score, support from colleagues and the supervisor was classified as low or high. Attitude towards paid employment was assessed by three statements with answers on a 3-point scale with ratings of "agree", "neutral", "do not agree" ("I would do a lot to have a paid job", "I always want to earn my own money with a paid job", "Paid employment is important for my self confidence"). Patients' attitude was classified as high motivation if they agreed with all three statements, and otherwise as low motivation.

At all of the measurements, currently present adaptations of the job due to joint complaints were asked

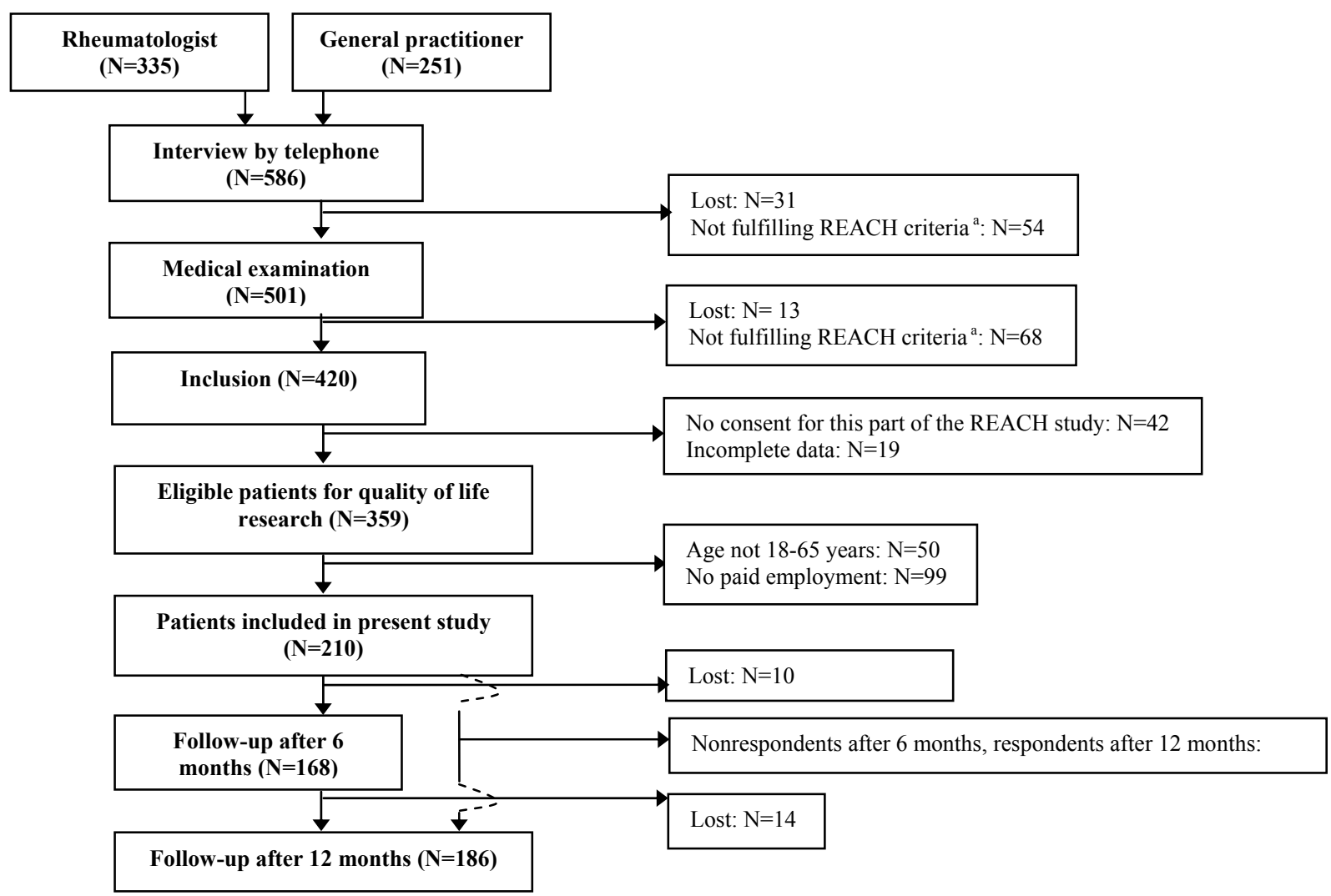

Figure 1. Inclusion and follow-up of the employed patients with early inflammatory joint conditions. (REACH = Rotterdam early arthritis cohort) ${ }^{a}$ Patients were included in REACH if (i) joint complaints existed for less than 12 months and (ii) arthritis in at least one joint or complaints in at least 2 joints in combination with other factors indicating inflammatory complaints was ascertained. [See the text.] 
about. The workers specified adaptations in worktasks, worktime, and the work environment by means of openended questions. Job adaptations were not included as predicting variables in the statistical analysis.

\section{Clinical characteristics and self-reported health}

Clinical characteristics were obtained at each measurement. The patients were classified into the following three mutually exclusive diagnostic groups on the basis of the diagnosis made by a rheumatologist: (i) definite or probable rheumatoid arthritis, (ii) specified or nonspecified mono- or oligo- or polyarthritis, nonrheumatoid arthritis, and (iii) inflammatory joint complaints without clinical synovitis. In the last group, the patients with artralgia or myalgia, osteoarthritis, or inflammatory complaints without further specification were included. A swollen joint count (44 joints) was categorized into no clinical synovitis, $1-2$ swollen joints, and $\geq 3$ swollen joints. The erythrocyte sedimentation rate was classified into low ( $\leq 20 \mathrm{~mm} /$ hour) or high $(>20 \mathrm{~mm} /$ hour). Since $89 \%$ of the patients with inflammatory joint complaints without clinical synovitis were classified into the group with a low erythrocyte sedimentation rate at baseline, they were also classified into this group if data were not available during the follow-up. The duration of inflammatory complaints was defined as the period between symptom onset and a medical examination and was dichotomized on the basis of the median number of weeks. The use of disease-modifying antirheumatic drugs (DMARD) was ascertained. Comorbidity was assessed and classified as no comorbid condition or at least one comorbid condition, since no large groups with the same comorbid condition could be differentiated.

At each measurement, self-reported health was asked about. Pain, physical functioning, and mental health were measured by the following three subscales of the Short Form-36 Health Survey (SF-36): bodily pain (2 items), physical functioning (10 items), and mental health (5 items), respectively $(29,30)$. The sum scores of the subscales can range from 0 to 100 , the higher scores indicating better health. Functional ability was assessed by the Health Assessment Questionnaire (20 items) (31). The scores of this questionnaire range from 0 to 3 , the higher scores indicating more disability. The subscales of the SF-36 and the Health Assessment Questionnaire were analyzed in tertiles. General fatigue during the past week was rated on a visual analogue scale ranging from 0 (no fatigue at all) to 100 (very high fatigue). Fatigue was classified as low or high on the basis of the median score.

Behavioral coping was assessed at baseline by the scale "decreasing activity to cope with pain" of the Coping of Rheumatic Stressors (CORS) questionnaire. This scale consists of eight items on a 4-point scale.
The sum score can range from 8 to 32, the higher scores indicating more frequent use of the coping strategy (32, 33). Behavioral coping was analyzed in tertiles.

\section{Sick leave and productivity at work}

In the Netherlands, sick leave is legally defined as not being able to work full-time, including both complete absence from work and work activities on restricted duty due to health problems. The latter was comprised of a small proportion of all workers on sick leave. In almost all situations, collective labor agreements require payment of full salary during the first 12 months and approximately $70 \%$ of the salary during the second 12 months. In this study, sick leave was measured at the baseline and after 6 months and 12 months of follow-up with the use of questions on the frequency and duration of sickness absence due to general causes in the past 6 months. For the duration of sick leave, the patients reported whether they experienced no sick leave or 1 to 7 days, 8 to 14 days, or $>2$ weeks of sick leave on a 4-point scale. These questions have been shown to have high specificity (91\%) and high sensitivity (79\%), and moderate agreement with register data (kappa, 0.50 and 0.54 , respectively,). The questions were the most accurate for those with sickness absence of $>14$ days (34). Hence sick leave was defined as reporting $>2$ weeks of sick leave in the past 6 months.

Productivity at work was assessed at 6 and 12 months of follow-up by two questions derived from the Quantity and Quality (QQ) instrument. The self-report questions addressed the quantity and quality of the work performed during the last workday compared with a normal workday. Answers were given on a numerical rating scale, 0 representing "nothing" and "very poor quality", respectively, and 10 representing "normal quantity" and "normal quality" (35, 36). Since the two questions on the quantity and quality of the work were highly correlated (Spearman $\mathrm{r}=0.73$ ), only the question on the quantity of the work was used in the analysis. The quantity of work was categorized into reduced productivity (score $<10$ ) and normal productivity (score $=10)$.

\section{Statistical analysis}

Predictors of sick leave and reduced productivity at work were studied in separate models by means of a logistic regression analysis with generalized estimating equations (GEE), suitable for the analysis of repeated measurements data. A 6-month time-lag model was chosen, implying that the measurement of a risk factor was related to the outcome measured 6 months later. In the analysis, those with one 6-month follow-up period had two measurements, and those with two 6-month periods of follow-up had 3 measurements. In the model, 
demographic and work characteristics were considered to be time independent, except for change of job and physical exertion. Clinical characteristics and self-reported health were considered to be time dependent, except for disease duration and behavioral coping, which were measured only at the baseline. The odds ratio (OR) was used as the measure of association, and it indicated the impact of a risk factor on sick leave and reduced productivity in the next 6 months.

The following procedure was used to identify predictors of sick leave and reduced productivity at work. First, all of the independent factors were analyzed with the use of a univariate logistic GEE model. Factors with a P-value below 0.20 were selected for further investigation. Second, a multivariate GEE model with demographic and work factors as independent factors was constructed by forward selection. The variables with a P-value of $\geq 0.05$ were selected, and age and gender were included in the model by default. Similarly, a multivariate GEE model with clinical factors and selfreported health as independent factors was used with forward selection, and the variables with a P-value of $\geq 0.05$ were selected. Third, the two multivariate models were combined to study the impact of demographic, work, clinical, and self-reported health variables on sick leave and reduced productivity at work during a period of 6 months. Independent variables with a P-value of $\geq 0.05$ were retained, as well as variables of borderline significance that caused a change of $\geq 10 \%$ in the coefficient of another significant variable in the model. The statistical analyses were performed with the statistical

Table 1. Demographic and work characteristics of the workers with early inflammatory joint conditions. (IQR = interquartile range)

\begin{tabular}{|c|c|c|c|c|c|}
\hline \multirow[t]{2}{*}{ Characteristics } & \multicolumn{5}{|c|}{ Baseline $(\mathrm{N}=210)$} \\
\hline & $\%$ & Mean & SD & Median & n IQR \\
\hline \multicolumn{6}{|l|}{ Demographic characteristics } \\
\hline Age (years) & . & 45 & 11 & . & . \\
\hline Female & 72 & . & . & . & . \\
\hline \multicolumn{6}{|l|}{ Education } \\
\hline High & 23 & . & . & . & . \\
\hline Intermediate & 35 & . & . & . & . \\
\hline Low & 42 & . & . & . & . \\
\hline \multicolumn{6}{|l|}{ Work characteristics } \\
\hline Workhours (number) & . & 31 & 13 & . & . \\
\hline Supervisor & 18 & . & . & . & . \\
\hline Prolonged clerical work & 36 & . & . & . & . \\
\hline Frequent manual materials handling & 22 & . & . & . & . \\
\hline Physical exertion (0-10a) & . & . & . & 6 & $3-8$ \\
\hline Job demands $\left(0-33^{a}\right)$ & . & . & . & 13 & $10-16$ \\
\hline Job control $\left(0-51^{a}\right)$ & . & . & . & 31 & $24-38$ \\
\hline Support from colleagues $\left(0-10^{a}\right)$ & . & . & . & 7 & $6-8$ \\
\hline Support from supervisor $\left(0-10^{a}\right)$ & . & . & . & 7 & $5-8$ \\
\hline
\end{tabular}

a Range of the scale on which the score was based. package STATA (8.0 SE, Stata Corporation, College Station, TX, USA).

\section{Results}

At the baseline, 210 workers seeking care for early inflammatory joint conditions participated in this study. The data of 168 persons were available after 6 months, and, after 12 months, 186 persons participated (figure 1). Altogether 24 (11\%) persons were lost to follow-up. They were significantly younger than the participants [39 (SD 11) versus 45 (SD 10) years], not classified as rheumatoid arthritis at baseline, and more frequently classified as inflammatory joint complaints without clinical synovitis (63\%). No differences were found for gender or for sick leave, pain, or physical functioning at the baseline.

Tables 1 and 2 describe the characteristics of the study population. At the baseline, the median disease duration was 15 (range 2-27) weeks. During the followup, the swollen joint count and erythrocyte sedimentation rates decreased. In addition, pain decreased and physical functioning improved in all of the diagnostic groups (table 2). After 6 months, 94\% of the rheumatoid arthritis patients, $33 \%$ of the patients with arthritis but not rheumatoid arthritis, and $9 \%$ of the patients classified as having inflammatory joint complaints without clinical synovitis received treatment with DMARD.

After 12 months, 11 persons had quit working and 2 of them attributed their work loss to their joint condition (table 3). Sick leave for more than 2 weeks in the past 6 months was reported by $26 \%$ of the workers at baseline, and by $27 \%$ and $17 \%$ after 6 and 12 months, respectively. Sick leave recurred for $66 \%$ of those with sick leave at the baseline and for $32 \%$ of those with sick leave at the 6-month visit. Reduced productivity recurred for $65 \%$ of the workers with reduced productivity at the 6-month visit. Sick leave and reduced productivity were strongly related; $72 \%$ of the workers who reported sick leave also reported reduced productivity. At least one job adaptation due to joint complaints was described by $39 \%$ of the persons after 12 months. Adaptations in worktasks were often combined with changes in worktimes or the environment. The workers with job adaptations more frequently had reduced productivity than those without adaptations (68\% versus 36\%). They also reported more sick leave (33\% versus $17 \%)$.

Table 4 shows that, in the univariate GEE analyses, low education and high physical load predicted sick leave, whereas being a supervisor reduced the likelihood of sick leave. High disease activity and worse self-reported health predicted sick leave, but diagnostic group and comorbidity had no impact. In the multivariate GEE 
Table 2. Clinical characteristics and self-reported health among the patients with early inflammatory joint conditions during a 1-year follow-up period. (IQR = interquartile range, SF-36 = Short Form-36 Health Survey, DMARD = disease-modifying antirheumatic drugs)

\begin{tabular}{|c|c|c|c|c|c|c|c|c|c|c|c|c|c|c|c|}
\hline & \multicolumn{5}{|c|}{ Baseline $(\mathrm{N}=210)$} & \multicolumn{5}{|c|}{6 months of follow-up ( $N=168)$} & \multicolumn{5}{|c|}{12 months of follow-up $(\mathrm{N}=186)$} \\
\hline & $\%$ & Mean & SD & Median & IQR & $\%$ & Mean & SD & Median & IQR & $\%$ & Mean & SD & Median & $I Q R$ \\
\hline \multicolumn{16}{|l|}{ Clinical factors } \\
\hline $\begin{array}{l}\text { Disease duration at } \\
\text { inclusion (weeks) }\end{array}$ & . & . & . & 15 & $7-27$ & . & . & . & . & . & . & . & . & . & . \\
\hline Diagnostic group & & & & . & . & & & & & & & & & & \\
\hline $\begin{array}{l}\text { Rheumatoid arthritis } \\
\text { Arthritis but not rheumatoid }\end{array}$ & 23 & . & . & . & . & 32 & . & . & . & . & 32 & . & . & . & . \\
\hline $\begin{array}{l}\text { arthritis } \\
\text { Inflammatory joint complaints }\end{array}$ & 35 & . & $\cdot$ & . & . & 29 & . & . & . & . & 34 & . & $\cdot$ & . & . \\
\hline without clinical synovitis & 42 & $\cdot$ & $\cdot$ & · & $\cdot$ & 39 & $\cdot$ & $\cdot$ & $\cdot$ & $\cdot$ & 34 & $\cdot$ & $\cdot$ & $\cdot$ & $\cdot$ \\
\hline \multicolumn{16}{|l|}{ Swollen joints (44 joints) } \\
\hline No swollen joints & 42 & . & . & . & . & 80 & . & . & . & . & 92 & . & $\cdot$ & . & . \\
\hline $1-2$ swollen joints & 29 & . & . & . & . & 16 & . & . & . & . & 2 & . & . & . & . \\
\hline$>2$ swollen joints & 29 & . & . & . & . & 4 & . & . & . & . & 6 & . & . & . & . \\
\hline $\begin{array}{l}\text { High erythrocyte sedimentation } \\
\text { rate (>20 mm/hour) }\end{array}$ & 34 & . & $\cdot$ & . & . & 15 & . & . & . & . & 11 & . & $\cdot$ & . & . \\
\hline Medical treatment with DMARD & 0 & . & . & . & . & 43 & . & . & . & . & 41 & . & . & . & . \\
\hline Comorbidity a & 38 & . & $\cdot$ & . & . & 42 & . & . & . & . & 45 & . & $\cdot$ & $\cdot$ & . \\
\hline \multicolumn{16}{|l|}{ Self-reported health } \\
\hline Bodily pain (SF-36) $\left(0-100^{b}\right)^{c}$ & . & 45 & 20 & . & . & . & 63 & 22 & . & . & . & 64 & 22 & . & . \\
\hline 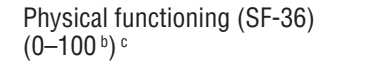 & $\cdot$ & 63 & 24 & . & . & $\cdot$ & 72 & 22 & $\cdot$ & $\cdot$ & $\cdot$ & 75 & 20 & $\cdot$ & . \\
\hline $\begin{array}{l}\text { Mental health (SF-36) }\left(0-100^{b}\right)^{c} \\
\text { Health assessment }\end{array}$ & . & 72 & 17 & . & . & . & 74 & 19 & . & . & . & 76 & 19 & $\cdot$ & . \\
\hline Questionnaire $\left(0-3^{\mathrm{b}}\right)^{\mathrm{d}}$ & . & . & . & 0.50 & $0.13-0.88$ & . & . & . & 0.25 & $0-0.63$ & . & . & . & 0.25 & $0-0.63$ \\
\hline Fatigue $\left(0-100^{\mathrm{b}}\right)^{\mathrm{e}}$ & . & . & . & 60 & $32-73$ & . & . & . & 52 & $26-72$ & . & . & . & 49 & $20-67$ \\
\hline $\begin{array}{l}\text { Decreasing activity to cope } \\
\text { with pain }\left(8-32^{b}\right)\end{array}$ & . & 15 & 5 & . & . & $\cdot$ & . & . & . & . & . & . & $\cdot$ & $\cdot$ & . \\
\hline
\end{tabular}

a Percentage of affirmative answers.

${ }^{\mathrm{b}}$ Range of the scale on which the score was based.

c Higher scores indicate better health.

${ }^{d}$ Higher scores indicate more functional disability.

${ }^{\mathrm{e}}$ Higher scores indicate more fatigue.

analysis, sick leave was predicted by frequent manual materials handling [OR 2.0, 95\% confidence interval (95\% CI) 1.0-4.0], a high level of bodily pain (OR 3.2, 95\% CI 1.3-7.5), and poor physical functioning (OR 4.4, 95\% CI 1.9-10), whereas the supervisors were less likely to report sick leave (OR $0.2,95 \%$ CI $0.1-0.7$ ) (table 4). Educational level, clinical factors, and reduced activities to cope with pain had no influence on sick leave when pain and function were taken into account. The impact of poor mental health on sick leave was borderline significant (OR 2.3, 95\% CI 0.9-5.8). The Health Assessment Questionniare was not included in the multivariate model since it was strongly associated with physical functioning as assessed by the SF-36 (Spearman $\mathrm{r}=0.64$ ).

The impact of demographic and work characteristics on productivity in the univariate GEE analysis resembled the pattern found for sick leave, although the relations were less strong and not significant for most factors (table 4). The presence of swollen joints, diagnostic group, and poor self-reported health influenced productivity. In the multivariate GEE analysis, reduced productivity at work was predicted by low support from colleagues (OR $2.2,95 \%$ CI 1.3-3.9), intermediate levels of pain (OR $3.1,95 \%$ CI 1.6-6.0), moderate or poor physical functioning (OR 2.1, 95\% CI 1.1-4.3, and OR 2.8, 95\% CI 1.2-6.5, respectively), and poor mental health (OR 2.1, 95\% CI 1.0-4.3), whereas productivity loss was less likely among the workers classified as having arthritis but not rheumatoid arthritis than among those with inflammatory joint complaints without clinical synovitis (OR 0.4 , 95\% CI 0.2-0.9) and those with rheumatoid arthritis (OR $0.3,95 \%$ CI $0.1-0.6$ ). For about half of the workers classified as having nonrheumatoid arthritis or arthritis at the baseline, clinical synovitis was transient after 6 months, as defined by no treatment with DMARD and no swollen joints. Furthermore, these workers had a 5.9-point better score for bodily pain after 6 months than both of the other diagnostic groups $(\mathrm{P}=0.10)$, and a 9.6-point better score after 12 months $(\mathrm{P}=0.00)$. The recurrence of reduced productivity was also lower (45\% versus $73 \%$ ).

When the work factors "being a supervisor" and "frequent manual materials handling" were added to the multivariate model of productivity, the findings were 
Table 3. Performance at work and job adaptations among workers with early inflammatory joint conditions during a 1-year follow-up period.

\begin{tabular}{|c|c|c|c|c|c|c|}
\hline \multirow[t]{2}{*}{ Work outcome } & \multicolumn{2}{|c|}{$\begin{array}{l}\text { Baseline } \\
(\mathrm{N}=210\end{array}$} & \multicolumn{2}{|c|}{$\begin{array}{c}\text { After } \\
6 \text { months } \\
(\mathrm{N}=168)\end{array}$} & \multicolumn{2}{|c|}{$\begin{array}{c}\text { After } \\
12 \text { months } \\
(\mathrm{N}=186)\end{array}$} \\
\hline & $\mathrm{N}$ & $\%$ & N & $\%$ & $\mathrm{~N}$ & $\%$ \\
\hline Quit employment & . & . & 6 & . & 11 & . \\
\hline Employed & 210 & . & 162 & . & 175 & . \\
\hline $\begin{array}{l}\text { Sick leave >2 weeks } \\
\text { in past } 6 \text { months }\end{array}$ & 54 & 26 & 44 & 27 & 29 & 17 \\
\hline $\begin{array}{l}\text { Reduced productivity } \\
\text { on last workday }\end{array}$ & . & . & 80 & 49 & 71 & 41 \\
\hline Work adaptation & 49 & 23 & 50 & 31 & 43 & 25 \\
\hline Tasks & 32 & 15 & 37 & 23 & 29 & 17 \\
\hline $\begin{array}{l}\text { Reduction in physical- } \\
\text { ly demanding tasks } \\
\text { Partial change in work }\end{array}$ & 20 & $\cdot$ & 21 & . & 16 & . \\
\hline tasks or job change & 9 & . & 8 & . & 7 & . \\
\hline Other adaptations & 3 & . & 8 & . & 6 & . \\
\hline Time & 22 & 10 & 22 & 14 & 15 & 9 \\
\hline $\begin{array}{l}\text { Reduction in hours } \\
\text { Change in distribution }\end{array}$ & 14 & $\cdot$ & 10 & . & 9 & $\cdot$ \\
\hline $\begin{array}{l}\text { of hours } \\
\text { Other adaptations }\end{array}$ & $\begin{array}{l}3 \\
5\end{array}$ & . & $\begin{array}{l}8 \\
4\end{array}$ & . & $\begin{array}{l}6 \\
0\end{array}$ & $\dot{r}$ \\
\hline Environment & 11 & 5 & 12 & 7 & 15 & 8 \\
\hline Desks, chairs, computer & 9 & . & 7 & . & 12 & . \\
\hline Other adaptations & 2 & . & 5 & . & 3 & . \\
\hline
\end{tabular}

in agreement with the impact of these factors on sick leave, although nonsignificant (OR $0.60,95 \%$ CI 0.29 1.23 , and OR $1.42,95 \%$ CI $0.66-3.02$, respectively). Furthermore, the impact of the risk factors on sick leave and reduced productivity at work did not differ between the first and second 6-month period. The observed relations between the work characteristics and outcomes did not differ among the workers with different levels of pain, physical functioning, and mental health, or between the diagnostic groups, when the interaction terms were added to the models.

\section{Discussion}

For the workers seeking care because of early inflammatory joint conditions, sick leave was predicted by high levels of pain, poor physical functioning, and frequent manual materials handling, whereas supervisors had a lower likelihood of reporting sick leave. The predictors of reduced productivity at work were increased levels of pain, intermediate or poor physical functioning, poor mental health, and low support from colleagues, whereas the workers classified as having arthritis or nonrheumatoid arthritis were less likely to report reduced productivity.
Some methodological aspects may have influenced our findings. Since the prevalence of inflammatory joint conditions in the general population is unknown, little insight exists with respect to the potential selection processes during the referral of patients by physicians to this inception cohort study. It is unlikely that the physicians selected patients on the basis of work characteristics. If selection bias occurred, it could be hypothesized that the physicians were more likely to notify patients for REACH if they reported serious complaints. An additional analysis showed that entering the study via either general practitioners or rheumatologists did not influence the performance at work. During the followup period, 24 patients were lost. Although these patients were younger and classified with less serious disease from a medical point of view, no differences existed for gender, pain, physical functioning, or sick leave at baseline. Therefore, loss to follow-up was not strongly influenced by the risk factors pain and function.

In this prospective cohort study of workers with early inflammatory joint conditions, clinical characteristics and self-reported health improved over time, and sick leave decreased. Two factors could explain the decrease in sick leave. First, medical treatment probably influenced pain, physical functioning, and the performance at work. Second, the decrease in sick leave may have been due to regression to the mean, since the patients were only included in this study when they sought care, and seeking care may be prompted by sick leave. As a consequence, it could be expected that sick leave was higher at the baseline than during the follow-up.

Self-reported pain and poor physical functioning already had an adverse effect on the performance at work in the early phase of inflammatory joint conditions, whereas the clinical factors "swollen joint count" and "erythocyte sedimentation rate", as parameters of inflammation, had no influence. Pain and reduced physical functioning are important consequences of musculoskeletal conditions (37), and they often result in sick leave $(13-15,18,38)$ or productivity loss $(13-15,18,38)$ in other musculoskeletal disorders. Therefore, this study adds to our knowledge that pain and physical functioning determine performance at work already in an early phase of this musculoskeletal condition, and that they are more important than the inflammatory parameters. Our findings were in agreement with the results of a cross-sectional study involving the same worker population. At baseline, when persons entered the study, high levels of pain (OR 4.1, 95\% CI 1.1-15.4) and poor physical functioning (OR 3.8, 95\%CI 1.2-11.4) were also strongly associated with sick leave in the past 6 months (39). No other clinical factor, except diagnostic group, had any predictive value. Workers with arthritis but not rheumatoid arthritis had a lower likelihood of reporting reduced productivity at work, relative to workers with 
Table 4. Predictors of sick leave and reduced productivity at work among workers with early inflammatory joint conditions in the GEE analyses. (GEE = generalized estimating equations)

\begin{tabular}{|c|c|c|c|c|c|c|c|c|}
\hline \multirow[t]{3}{*}{ Predictor } & \multicolumn{4}{|c|}{ Sick leave $\left(\mathrm{N}=307^{\mathrm{a}}\right)$} & \multicolumn{4}{|c|}{ Reduced productivity at work $\left(\mathrm{N}=303^{\mathrm{b}}\right.$ ) } \\
\hline & \multicolumn{2}{|c|}{ Univariate } & \multicolumn{2}{|c|}{ Multivariate } & \multicolumn{2}{|c|}{ Univariate } & \multicolumn{2}{|c|}{ Multivariate } \\
\hline & $\mathrm{OR}$ & $95 \% \mathrm{Cl}$ & $\mathrm{OR}$ & $95 \% \mathrm{Cl}$ & $\mathrm{OR}$ & $95 \% \mathrm{Cl}$ & $\mathrm{OR}$ & $95 \% \mathrm{Cl}$ \\
\hline \multicolumn{9}{|l|}{ Demographic and work characteristics } \\
\hline Age (years) & 1.02 & $0.99-1.04$ & 1.01 & $0.99-1.04$ & 1.01 & $0.99-1.04$ & 1.00 & $0.97-1.03$ \\
\hline Gender (male versus female) & 0.94 & $0.50-1.80$ & 1.00 & $0.49-2.04$ & 0.80 & $0.45-1.41$ & 0.95 & $0.50-1.79$ \\
\hline Ethnicity (non-Dutch versus Dutch origin) & $1.78^{c}$ & $0.91-3.48$ & $\cdot$ & . & $1.90^{\mathrm{d}}$ & $1.04-3.45$ & $\cdot$ & • \\
\hline \multicolumn{9}{|l|}{ Education } \\
\hline High & 1.00 & . & . & . & 1.00 & . & . & . \\
\hline Intermediate & 1.69 & $0.71-3.98$ & . & . & 1.52 & $0.78-2.98$ & . & . \\
\hline Low & $2.80^{d}$ & $1.25-6.29$ & . & . & 1.62 & $0.84-3.15$ & . & . \\
\hline Supervisor & $0.23^{d}$ & $0.08-0.63$ & $0.24^{d}$ & $0.08-0.70$ & 0.79 & $0.40-1.57$ & . & . \\
\hline Prolonged clerical work & 0.65 & $0.35-1.19$ & . & . & 0.67 & $0.40-1.13$ & . & . \\
\hline Frequent manual materials handling & $1.98^{d}$ & $1.10-3.56$ & $1.96^{c}$ & $0.97-3.98$ & 1.48 & $0.79-2.76$ & . & · \\
\hline High physical exertion $\left(>6.0^{\mathrm{e}}\right)$ & $2.32^{d}$ & $1.28-4.22$ & . & . & 1.38 & $0.84-2.28$ & . & . \\
\hline High job demands $\left(\geq 13^{\mathrm{e}}\right)$ & 1.32 & $0.74-2.33$ & . & . & 0.97 & $0.59-1.61$ & . & . \\
\hline Low job control $\left(\leq 30^{\mathrm{e}}\right)$ & $1.70^{c}$ & $0.96-3.04$ & . & . & 1.17 & $0.71-1.91$ & . & . \\
\hline Low support from colleagues $\left(\geq 7.0^{\mathrm{e}}\right)$ & $1.69^{c}$ & $0.94-3.04$ & . & . & $1.64^{c}$ & $0.99-2.72$ & $2.21^{d}$ & $1.27-3.86$ \\
\hline Low support from the supervisor $\left(\geq 7.0^{\mathrm{e}}\right)$ & 0.83 & $0.48-1.44$ & . & . & 0.86 & $0.51-1.45$ & . & . \\
\hline High motivation to be in paid employment & 0.64 & $0.36-1.13$ & . & . & 1.32 & $0.80-2.20$ & . & . \\
\hline \multicolumn{9}{|l|}{ Clinical characteristics and self-reported health } \\
\hline \multicolumn{9}{|l|}{ Diagnosis } \\
\hline Inflammatory joint complaints, no synovitis & 1.00 & . & . & . & 1.00 & . & 1.00 & . \\
\hline Arthritis, not rheumatoid arthritis & 1.20 & $0.63-2.28$ & . & . & $0.59^{c}$ & $0.32-1.09$ & $0.44^{d}$ & $0.22-0.90$ \\
\hline Rheumatoid arthritis & 1.17 & $0.59-2.35$ & . & . & 1.65 & $0.90-3.03$ & 1.61 & $0.80-3.25$ \\
\hline \multicolumn{9}{|l|}{ Swollen joints } \\
\hline No swollen joints & 1.00 & . & . & . & 1.00 & . & . & . \\
\hline 1-2 swollen joints & 1.59 & $0.84-3.00$ & . & . & $1.98^{d}$ & $1.14-3.42$ & . & . \\
\hline$>2$ swollen joints & $2.55^{d}$ & $1.38-4.70$ & . & . & $1.55^{c}$ & $0.92-2.61$ & . & . \\
\hline High erythrocyte sedimentation rate (>20 mm/hour) & $3.04^{d}$ & $1.68-5.52$ & . & . & 1.12 & $0.63-1.97$ & . & . \\
\hline Disease duration at inclusion (long versus short) & $0.62^{c}$ & $0.35-1.09$ & . & . & 0.68 & $0.41-1.13$ & . & . \\
\hline Comorbidity (yes versus no) & 1.48 & $0.85-2.58$ & . & . & 1.25 & $0.77-2.03$ & . & . \\
\hline \multicolumn{9}{|l|}{ Bodily pain } \\
\hline Low $\left(\geq 52^{e}\right)$ & 1.00 & . & 1.00 & . & 1.00 & . & 1.00 & . \\
\hline Intermediate $\left(39-51^{\mathrm{e}}\right)$ & 1.57 & $0.77-3.18$ & 1.27 & $0.58-2.78$ & $3.21^{\mathrm{d}}$ & $1.89-5.46$ & $3.11^{\mathrm{d}}$ & $1.61-6.02$ \\
\hline $\operatorname{High}\left(\leq 38^{e}\right)$ & $7.96^{d}$ & $4.02-15.8$ & $3.17^{d}$ & $1.34-7.49$ & $2.61^{d}$ & $1.47-4.63$ & 1.91 & $0.83-4.39$ \\
\hline \multicolumn{9}{|l|}{ Physical functioning } \\
\hline $\operatorname{Good}(\geq 76)^{\mathrm{e}}$ & 1.00 & . & 1.00 & & 1.00 & . & 1.00 & . \\
\hline Moderate $\left(54-75^{\mathrm{e}}\right)$ & 1.23 & $0.57-2.64$ & 1.22 & $0.56-2.66$ & $2.24^{d}$ & $1.20-4.19$ & $2.14^{d}$ & $1.06-4.30$ \\
\hline Poor $\left(\leq 53^{\mathrm{e}}\right)$ & $7.81^{\mathrm{d}}$ & $3.90-15.7$ & $4.38^{d}$ & $1.88-10.2$ & $3.93^{d}$ & $2.07-7.47$ & $2.84^{d}$ & $1.24-6.50$ \\
\hline \multicolumn{9}{|l|}{ Health Assessment Questionnaire } \\
\hline $\operatorname{Good}\left(\leq 0.12^{\mathrm{e}}\right)$ & 1.00 & . & . & . & 1.00 & . & . & . \\
\hline Moderate $\left(0.13-0.63^{\mathrm{e}}\right)$ & 0.85 & $0.39-1.86$ & . & . & $1.96^{d}$ & $1.11-3.45$ & . & . \\
\hline Poor $(\geq 0.64 \mathrm{e})$ & $2.91^{d}$ & $1.52-5.57$ & . & . & $4.17^{\mathrm{d}}$ & $2.25-7.75$ & . & . \\
\hline \multicolumn{9}{|l|}{ Mental health } \\
\hline Good $\left(\geq 81^{e}\right)$ & 1.00 & . & . & . & 1.00 & . & 1.00 & . \\
\hline Moderate $\left(65-80^{\mathrm{e}}\right)$ & $2.05^{c}$ & $0.91-4.64$ & . & . & 1.26 & $0.73-2.17$ & 0.82 & $0.44-1.54$ \\
\hline Poor $\left(\leq 64^{\mathrm{e}}\right)$ & $4.93^{d}$ & $2.29-10.6$ & . & . & $2.60^{d}$ & $1.46-4.64$ & $2.11^{d}$ & $1.04-4.26$ \\
\hline Fatigue $\left(\geq 61^{\mathrm{e}}\right)$ & $1.72^{d}$ & $1.06-2.78$ & . & . & $1.65^{c}$ & $0.99-2.73$ & . & . \\
\hline \multicolumn{9}{|l|}{ Decreasing activity to cope with pain $\left(8-32^{\mathrm{e}}\right)$} \\
\hline Low & 1.00 & . & . & . & 1.00 & . & . & . \\
\hline Intermediate & $2.49^{d}$ & $1.06-5.87$ & . & . & 1.36 & $0.72-2.59$ & . & . \\
\hline High & $4.13^{d}$ & $1.91-8.96$ & . & . & $2.44^{d}$ & $1.30-4.57$ & . & . \\
\hline
\end{tabular}

a Altogether 162 persons completed the first 6-month period, 145 persons completed the second 6-month period, with 142 persons with complete data for both periods.

${ }^{\mathrm{b}}$ Altogether 160 persons completed the first 6-month period, 143 persons completed the second 6-month period with 139 persons with complete data for both 6-month periods.

c $0.05<P<0.10$

d $P<0.05$.

e Range of the scale on which the score was based. 
rheumatoid arthritis and workers with inflammatory joint conditions without clinical synovitis. In this patient group, clinical synovitis was transient (self-limiting) for a substantial proportion of the patients, as one would expect (40). The transient nature of the complaints was illustrated by the fact that these patients did not receive treatment with DMARD and also had no swollen joints after 6 months. Moreover, self-reported pain was lower in this diagnostic group during the follow-up. Given the transient nature of the complaints, it is very likely that most of these workers had no complaints when filling out the questionnaire on productivity loss at work.

Apart from the experience of pain and decreased physical functioning, the job characteristics "manual materials handling", "being a supervisor", and "support from colleagues" predicted performance at work. It can be hypothesized that pain and functional limitations become especially troublesome in jobs with strenuous work conditions. Frequent manual materials handling increases the mechanical loading of the joints, which, in turn, may result in the exacerbation of joint complaints (41). Likewise, supervisors have more control over the planning and organization of their activities at work and thus may avoid strenuous work conditions when their complaints flair up (42). The positive effects of support from colleagues could also reflect increased possibilities for workers with complaints to adjust their workload when needed. This possibility could be illustrated by a qualitative study, in which a substantial proportion of the persons with longstanding rheumatoid arthritis reported that their colleagues helped with physical aspects of the job, such as lifting, reaching, and typing (43). It is of interest to gain more insight into the mechanisms of workers with inflammatory joint complaints so that their work conditions can be tailored to their temporary pain and functional limitations. The workers with early inflammatory joint conditions frequently described adaptations of the job. An additional analysis showed that, among the workers without any adaptation at baseline, the likelihood of adaptations was increased among those with poor physical functioning (OR 7.2, 95\% CI 2.9-18) and decreased among those with prolonged clerical work (OR 0.2, 95\% CI 0.1-0.4). In a recent study, a higher proportion of the workers with early arthritis reported job adaptations than in our study (ie, 29\% versus 23\% at baseline and $42 \%$ versus $25 \%$ after 12 months) (44). This difference could be due to worse physical functioning. Since little is known about the influence of early adaptations on the relation between job characteristics and performance at work, we recommend future studies to address their influence.

Our study showed that physicians can support workers' performance at work with early inflammatory joint conditions by targeting pain and physical functioning, in addition to disease activity. In addition to medical treatment, patient education programs may improve function and pain, although more insight is needed into their impact in different musculoskeletal diseases and their timing $(45,46)$. Early job-related interventions that reduce physical workload and increase control over the organization and planning of activities may avoid negative consequences of inflammatory joint complaints on performance at work.

Among the workers with early inflammatory joint conditions, self-reported pain and physical functioning affected performance at work, together with manual materials handling and lack of support from colleagues. Early treatment should target pain and physical functioning, and job interventions should aim at reducing physical workload and increasing coworker support.

\section{Acknowledgments}

This study was supported by The Dutch Arthritis Association.

\section{References}

1. Lacaille D, Hogg RS. The effect of arthritis on working life expectancy. J Rheumatol. 2001;28:2315-9.

2. Mau W, Listing J, Huscher D, Zeidler H, Zink A. Employment across chronic inflammatory rheumatic diseases and comparison with the general population. J Rheumatol. 2005;32:721-8.

3. Geuskens GA, Burdorf A, Hazes JM. Consequences of rheumatoid arthritis for performance of social roles-a literature review. J Rheumatol. 2007;34:1248-60.

4. Sokka T, Pincus T. Markers for work disability in rheumatoid arthritis. J Rheumatol. 2001;28:1718-22.

5. Verstappen SM, Bijlsma JW, Verkleij H, Buskens E, Blaauw AA, ter Borg EJ, et al. Overview of work disability in rheumatoid arthritis patients as observed in cross-sectional and longitudinal surveys. Arthritis Rheum. 2004;51:488-97.

6. Burdorf A. Economic evaluation in occupational health-its goals, challenges, and opportunities [editorial]. Scand J Work Environ Health. 2007;33(3):161-4.

7. Escorpizo R, Bombardier C, Boonen A, Hazes JM, Lacaille $\mathrm{D}$, Strand V, et al. Worker productivity outcome measures in arthritis. J Rheumatol. 2007;34:1372-80.

8. Uegaki K, de Bruijne MC, Anema JR, van der Beek AJ, van Tulder MW, van Mechelen W. Consensus-based findings and recommendations for estimating the costs of health-related productivity loss from a company's perspective. Scand J Work Environ Health. 2007;33(3):122-130.

9. Dadoniene J, Stropuviene S, Venalis A, Boonen A. High work disability rate among rheumatoid arthritis patients in Lithuania. Arthritis Rheum. 2004;51:433-9.

10. Kleinman NL, Brook RA, Patel PA, Melkonian AK, Brizee TJ, Smeeding JE, et al. The impact of gout on work absence and productivity. Value Health. 2007;10:231-7.

11. Muchmore L, Lynch WD, Gardner HH, Williamson T, Burke T. Prevalence of arthritis and associated joint disorders in 
an employed population and the associated healthcare, sick leave, disability, and workers' compensation benefits cost and productivity loss of employers. J Occup Environ Med. 2003;45:369-78.

12. Kessler RC, Maclean JR, Petukhova M, Sarawate CA, Short L, $\mathrm{Li}$ TT, et al. The effects of rheumatoid arthritis on labor force participation, work performance, and healthcare costs in two workplace samples. J Occup Environ Med. 2008;50:88-98.

13. Bergstrom G, Bodin L, Bertilsson H, Jensen IB. Risk factors for new episodes of sick leave due to neck or back pain in a working population - a prospective study with an 18-month and a three-year follow-up. Occup Environ Med. 2007;64:27987.

14. Coste J, Delecoeuillerie G, Cohen de Lara A, Le Parc JM, Paolaggi JB. Clinical course and prognostic factors in acute low back pain: an inception cohort study in primary care practice. BMJ. 1994;308:577-80.

15. Elders LA, Heinrich J, Burdorf A. Risk factors for sickness absence because of low back pain among scaffolders: a 3-year follow-up study. Spine. 2003;28:1340-6.

16. Hoogendoorn WE, Bongers PM, de Vet HC, Ariens GA, van Mechelen W, Bouter LM. High physical work load and low job satisfaction increase the risk of sickness absence due to low back pain: results of a prospective cohort study. Occup Environ Med. 2002;59:323-8.

17. IJzelenberg W, Burdorf A. Risk factors for musculoskeletal symptoms and ensuing health care use and sick leave. Spine. 2005;30:1550-6.

18. Kuijpers T, van der Windt DA, van der Heijden GJ, Twisk JW, Vergouwe Y, Bouter LM. A prediction rule for shoulder pain related sick leave: a prospective cohort study. BMC Musculoskelet Disord. 2006;7:97.

19. Li X, Gignac MA, Anis AH. The indirect costs of arthritis resulting from unemployment, reduced performance, and occupational changes while at work. Med Care. 2006;44:304-10.

20. Burton WN, Chen CY, Schultz AB, Conti DJ, Pransky G, Edington DW. Worker productivity loss associated with arthritis. Dis Manage. 2006;9:131-43.

21. de Buck PD, de Bock GH, van Dijk F, van den Hout WB, Vandenbroucke JP, Vliet Vlieland TP. Sick leave as a predictor of job loss in patients with chronic arthritis. Int Arch Occup Environ Health. 2006;80:160-70.

22. Reisine S, Fifield J, Walsh SJ, Feinn R. Factors associated with continued employment among patients with rheumatoid arthritis: a survival model. J Rheumatol. 2001;28:2400-8.

23. Keij I. Numbers of foreigners according to various definitions. Maandstat Bevolking. 2000;48:14-7.

24. Hildebrandt VH, Bongers PM, van Dijk FJ, Kemper HC, Dul J. Dutch Musculoskeletal Questionnaire: description and basic qualities. Ergonomics. 2001;44:1038-55.

25. Elders LA, Burdorf A. Interrelations of risk factors and low back pain in scaffolders. Occup Environ Med. 2001;58:597603.

26. Borg G. Psychophysical scaling with applications in physical work and the perception of exertion. Scand J Work Environ Health. 1990;16 suppl 1:55-8.

27. Karasek R, Baker D, Marxer F, Ahlbom A, Theorell T. Job decision latitude, job demands, and cardiovascular disease a prospective study of Swedish men. Am J Public Health. 1981;71:694-705.

28. IJzelenberg W, Molenaar D, Burdorf A. Different risk factors for musculoskeletal complaints and musculoskeletal sickness absence. Scand J Work Environ Health. 2004;30(1):56-63.

29. Ware JE Jr, Sherbourne CD. The MOS 36-item short-form health survey (SF-36), I: conceptual framework and item selection. Med Care. 1992;30:473-83.

30. Aaronson NK, Muller M, Cohen PD, Essink-Bot ML, Fekkes M, Sanderman R, et al. Translation, validation, and norming of the Dutch language version of the SF-36 Health Survey in community and chronic disease populations. J Clin Epidemiol. 1998;51:1055-68.

31. Fries JF, Spitz P, Kraines RG, Holman HR. Measurement of patient outcomes in arthritis. Arthritis Rheum. 1980:137-45.

32. van Lankveld W, van't Pad Bosch P, van de Putte L, Naring G, van der Staak C. Disease-specific stressors in rheumatoid arthritis: coping and well-being. Br J Rheumatol. 1994;33:106773.

33. van Lankveld W, Naring G, van der Staak C, van 't Pad Bosch P, van de Putte L. De ontwikkeling van de CORS: coping met reuma stressoren [Development of the CORS: coping with rheumatic stressors]. Gedrag Gezond. 1993;21:40-8.

34. Burdorf A, Post W, Bruggeling T. Reliability of a questionnaire on sickness absence with specific attention to absence due to back pain and respiratory complaints. Occup Environ Med. 1996;53:58-62.

35. Brouwer WB, Koopmanschap MA, Rutten FF. Productivity losses without absence: measurement validation and empirical evidence. Health Policy. 1999;48:13-27.

36. Meerding WJ, IJzelenberg W, Koopmanschap MA, Severens JL, Burdorf A. Health problems lead to considerable productivity loss at work among workers with high physical load jobs. J Clin Epidemiol. 2005;58:517-23.

37. Picavet HS, Hoeymans N. Health related quality of life in multiple musculoskeletal diseases: SF-36 and EQ-5D in the DMC3 study. Ann Rheum Dis. 2004;63:723-9.

38. Boström M, Dellve L, Thomée S, Hagberg M. Risk factors for generally reduced productivity - a prospective cohort study of young adults with neck or upper-extremity musculoskeletal symptoms. Scand J Work Environ Health. 2008;34(2):120 32.

39. Geuskens GA, Hazes JMW, Barendregt PCM, Burdorf A. Work and sick leave among patients with early inflammatory joint complaints. Arthritis Rheum. 2008; 59(10):1458-66.

40. Visser H, le Cessie S, Vos K, Breedveld FC, Hazes JM. How to diagnose rheumatoid arthritis early: a prediction model for persistent (erosive) arthritis. Arthritis Rheum. 2002;46:357-65.

41. Allaire S, Wolfe F, Niu J, Baker N, Michaud K, LaValley M. Extent of occupational hand use among persons with rheumatoid arthritis. Arthritis Rheum. 2006;55:294-9.

42. Lacaille D, White MA, Backman CL, Gignac MA. Problems faced at work due to inflammatory arthritis: new insights gained from understanding patients' perspective. Arthritis Rheum. 2007;57:1269-79.

43. Mancuso CA, Paget SA, Charlson ME. Adaptations made by rheumatoid arthritis patients to continue working: a pilot study of workplace challenges and successful adaptations. Arthritis Care Res. 2000;13:89-99.

44. Zirkzee EJ, Sneep AC, de Buck PD, Allaart CF, Peeters AJ, Ronday HK, et al. Sick leave and work disability in patients with early arthritis. Clin Rheumatol. 2007;27(1):11-9.

45. Li LC. If knowledge is power, why don't rheumatoid arthritis education programs show better outcomes? J Rheumatol. 2007;34:1645-6.

46. Riemsma RP, Taal E, Kirwan JR, Rasker JJ. Systematic review of rheumatoid arthritis patient education. Arthritis Rheum. 2004;51:1045-59.

Received for publication: 7 June 2008 